\title{
A Novel Synthesis of Nanostructured ZnO via Thermal Oxidation of Zn Nanowires Obtained by a Green Route
}

\author{
Adriana Veloso Maciel, Wagner da Nova Mussel, Vânya Márcia Duarte Pasa \\ ${ }^{1}$ Department of Chemistry, Universidade Federal de Minas Gerais, Belo Horizonte, Brazil. \\ Email: vmdpasa@terra.com.br
}

Received September $9^{\text {th }}, 2010$; revised November $1^{\text {st }}, 2010$; accepted November $5^{\text {th }}, 2010$.

\begin{abstract}
$\mathrm{ZnO}$ nanowires were synthesised in a green and novel, two-step process: (1) the production of Zn nanowires by carbothermal reduction of a mixture of ZnO/biopitch (Eucalyptus sp. tar pitch) at $900^{\circ} \mathrm{C}$ for $1 \mathrm{~h}$ in a quartz tube placed in an electric furnace in a $\mathrm{N}_{2}$ atmosphere and (2) the oxidation of the as-prepared Zn nanowires in air at $300^{\circ} \mathrm{C}$ for $3 \mathrm{~h}$ and $6 \mathrm{~h}$ and at $400^{\circ} \mathrm{C}$ for $3 \mathrm{~h}$. The structural properties and phase compositions of the oxidised samples were studied by $X$-ray diffraction (XRD), and the morphologies were investigated by scanning electron microscopy (SEM). The XRD results demonstrated the formation of $\mathrm{ZnO}$ phase, as the main product. The oxidised products exhibited good crystallinity. Maximal conversion of the $\mathrm{Zn}$ nanowires into $\mathrm{ZnO}$ nanowires $(99 \%)$ resulted from oxidation of the sample for $3 \mathrm{~h}$ in air at $300^{\circ} \mathrm{C}$. The formation of $\mathrm{ZnO}$ was also confirmed by Fourier transform infrared (FTIR) spectroscopy.
\end{abstract}

Keywords: Biopitch, Zn Nanowires, Thermal Oxidation, ZnO Nanowires, XRD, FTIR

\section{Introduction}

Zinc oxide $(\mathrm{ZnO})$ exhibits many interesting properties, such as a wide direct bandgap (3.37 eV), high binding energy of the free excitation $(60 \mathrm{meV})$ at room temperature, high photoconductivity, and important piezoelectric and pyroeletric properties [1-2]. Due to these properties, $\mathrm{ZnO}$ has attracted considerable attention for potential applications in various electronic and optoelectronic devices.

A variety of methods, including thermal evaporation [3], hydrothermal processing [4], chemical vapour deposition [5], metal-organic CVD [6], and carbothermal reduction [7], have been widely used to prepare different $\mathrm{ZnO}$ nanostructures. An alternative process for preparing $\mathrm{ZnO}$ nanowires involves the synthesis of zinc nanoparticles followed by oxidation. The thermal oxidation method has attracted interest due to its simplicity, low cost, lower temperatures, and the lack of a need for a catalyst. Recently, $\mathrm{ZnO}$ nanoneedles were selectively grown on the facets of zinc microstructures by thermal oxidation in ambient atmosphere at temperatures from 250 to $400^{\circ} \mathrm{C}$ for $4 \mathrm{~h}$ [8]. $\mathrm{ZnO}$ nanowires and nanorods have been prepared at an optimal pressure by simple thermal oxidation of wire-like $\mathrm{Zn}$ precursors at different temperatures [9].
Wang et al. synthesised $\mathrm{ZnO}$ nanoparticles by oxidising $\mathrm{Zn}$ nanoparticles prepared through arc discharge in air at $250^{\circ} \mathrm{C}, 300^{\circ} \mathrm{C}$ and $350^{\circ} \mathrm{C}$ for different periods of time [10]. $\mathrm{ZnO}$ films formed by the oxidation of $\mathrm{Zn}$ thin films have been reported [2,11,12]. $\mathrm{ZnO}$ nanowires have been formed by annealing $\mathrm{Zn}$ nanowires at $500^{\circ} \mathrm{C}$ for $1 \mathrm{~h}$; the nanowires were synthesised by heating a $\mathrm{ZnO}$ and graphite mixture [13]. However, little attention has been given to the preparation of $\mathrm{ZnO}$ by thermal oxidation of as-prepared metallic zinc nanoparticles by the carbothermal reduction process.

This paper describes $\mathrm{ZnO}$ nanostructures obtained by the thermal oxidation of $\mathrm{Zn}$ nanowires synthesised by a green carbothermal reduction method. A mixture of $\mathrm{ZnO} /$ biopitch was heated, and the gases that evolved during the biopitch pyrolysis and the special carbon generated during the process promoted the reduction of $\mathrm{ZnO}$ into metallic $\mathrm{Zn}$. The controlled experimental conditions that allowed the growth of $\mathrm{Zn}$ nanowires were recently presented in the literature [14]. The synthesis of nanostructured $\mathrm{ZnO}$ using these $\mathrm{Zn}$ nanowires as precursors was performed by our research group, and the best results are presented for the first time in this paper. This green method of synthesis is very simple and catalyst-free and 
will probably have industrial interest due to its low cost (because biopitch is a remnant of the charcoal production industry) and the fact that the process presents soft experimental conditions. Environmental benefits are also realised because the process uses renewable carbon (biopitch) instead of petroleum pitch, graphite or carbon nanotubes.

\section{Experimental}

\subsection{Synthesis of the $\mathrm{Zn}$ Nanowires - Step 1}

In the present study, zinc nanowires were synthesised by a new carbothermal reduction process by heating a mixture of high-purity $\mathrm{ZnO}$ (SYNTH, 99.0\% minimum purity) powder and biopitch (Eucalyptus $s p$. tar pitch), using optimal experimental conditions previously obtained by our research group and presented in the literature [14]. The source material, pure $\mathrm{ZnO}$ powder mixed with biopitch (molar ratio 1:1), was placed in a quartz boat, which was placed at the centre of a quartz tube and inserted into a horizontal tube furnace. The furnace was heated to $900^{\circ} \mathrm{C}$ at a heating rate of $3^{\circ} \mathrm{C} / \mathrm{min}$ and kept at $900^{\circ} \mathrm{C}$ for $1 \mathrm{~h}$ under a constant flow of nitrogen, which was used as the carrier gas during the process. After thermal treatment, the furnace was naturally cooled to room temperature. The fluffy, dark, gray products that formed on the inner wall of the quartz tube were collected. No catalysts or templates were needed for material growth through this method.

\subsection{Synthesis of the $\mathrm{ZnO}$ Nanowires by Thermal Oxidation of $\mathrm{Zn}$ Nanowires - Step 2}

The as-prepared zinc nanowires were put into a quartz boat and loaded into the centre of a quartz tube with two open ends, which was placed in a horizontal furnace. The $\mathrm{Zn}$ nanowires were then heated in air under different conditions to determine the best parameters for promoting $\mathrm{Zn}$ oxidation. The $\mathrm{Zn}$ nanowires were heated to $300^{\circ} \mathrm{C}$ for $3 \mathrm{~h}$, to $300^{\circ} \mathrm{C}$ for $6 \mathrm{~h}$, and to $400^{\circ} \mathrm{C}$ for $3 \mathrm{~h}$ in air to promote oxidation into $\mathrm{ZnO}$ nanostructures. Subsequently, the furnace was cooled to room temperature. The as-synthesised products were then identified as samples $\mathrm{A}, \mathrm{B}$ and $\mathrm{C}$, as shown in the schematic diagram of the process in Figure 1.

\subsection{Characterization of the as-Synthesised Products}

The morphologies and compositions of the as-synthesised products were characterised by a scanning electron microscope (SEM, Philips XL 30FEG at $30 \mathrm{KV}$ ) equiped with an energy-dispersive X-ray spectroscope (EDS,

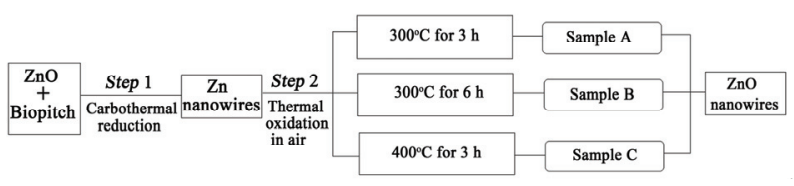

Figure 1. Schematic diagram of the synthesis of $\mathrm{ZnO}$ nanowires.

JEOL JXA-8900RL at $15 \mathrm{KV}$ and $13 \mathrm{~mA}$ ).

The phases and crystallographies of the products were characterised using X-ray diffraction (XRD), which was carried out on a Siemens D5000 diffractometer equipped with a $\mathrm{CuK} \alpha(\lambda=1.54178 \AA)$ radiation tube operating at $40 \mathrm{KV}$ and $30 \mathrm{~mA}$ at room temperature with a time constant of $0.5 \mathrm{~s}$ under a spinning sample holder at 60 cycles per minute, attempting to avoid any preferred orientation. The phases and crystallographies of the products were characterised using X-ray diffraction (XRD), which was carried out on a Siemens D5000 diffractometer equipped with a $\mathrm{CuK} \alpha(\lambda=1.54178 \AA)$ radiation tube operating at $40 \mathrm{KV}$ and $30 \mathrm{~mA}$ at room temperature with a time constant of $0.5 \mathrm{~s}$ under a spinning sample holder at 60 cycles per minute, attempting to avoid any preferred orientation. The scanning step was $0.05^{\circ} 2 \theta /$ step. Crystalline phase identification was performed by comparing the sample diffractogram to the PDF2 database from JCDS [15]. The diffraction pattern was fit using the Rietveld algorithm to model the peak profiles, obtain the most reliable lattice parameters and allow quantitative phase analysis.

The oxidised products were also characterised by Fourier transform infrared FTIR spectroscopy (FT-IR, ABB BOMEM MBSeries) in the range of $4000-250 \mathrm{~cm}^{-1}$. FTIR analyses were performed on powders prepared by the $\mathrm{KBr}$-pellet technique.

\section{Results and Discussion}

\subsection{Characterization of the as-Synthesized $\mathrm{Zn}$ Nanowires - Step 1}

Figure 2 represents X-rays diffraction (XRD) patterns of the dark, gray product deposited onto the inner wall of the quartz tube after step 1 (Figure 1).

The SEM image shown in Figure 3 gives a general view of the morphology of the as-deposited product, observed as a large quantity of entangled and curved wirelike structures. In general, the zinc nanowires are several micrometers long and about $70 \mathrm{~nm}$ in diameter.

\subsection{Characterization of the as-Synthesised $\mathrm{ZnO}$ Nanowires - Step 2}

The X-ray diffraction patterns of samples A, B and C obtained from the oxidation of $\mathrm{Zn}$ nanowires in air are shown in Figure 4. 


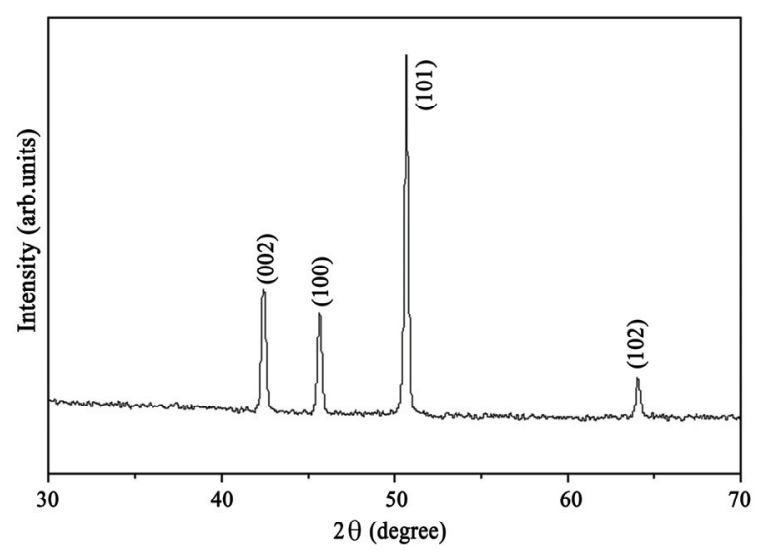

Figure 2. X-ray diffraction pattern of the metallic $\mathrm{Zn}$ nanowires obtained from the carbothermal reduction process.

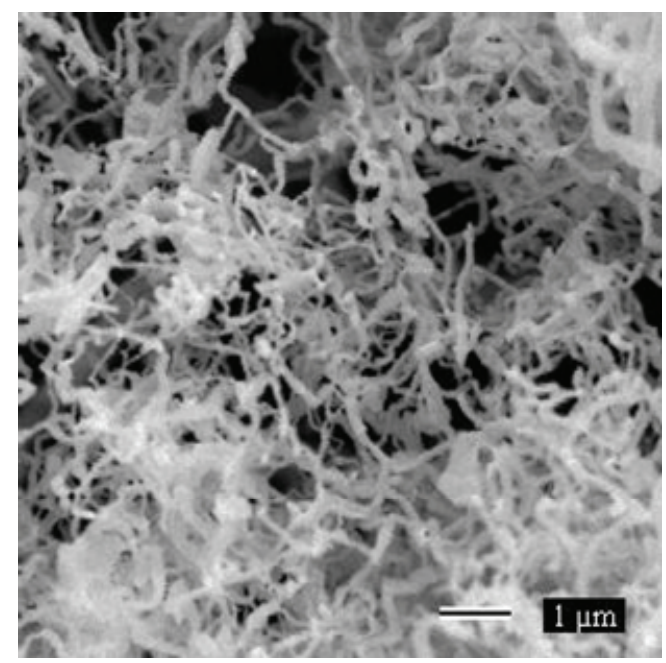

Figure 3. SEM image of the metallic Zn nanowires obtained from the carbothermal reduction.

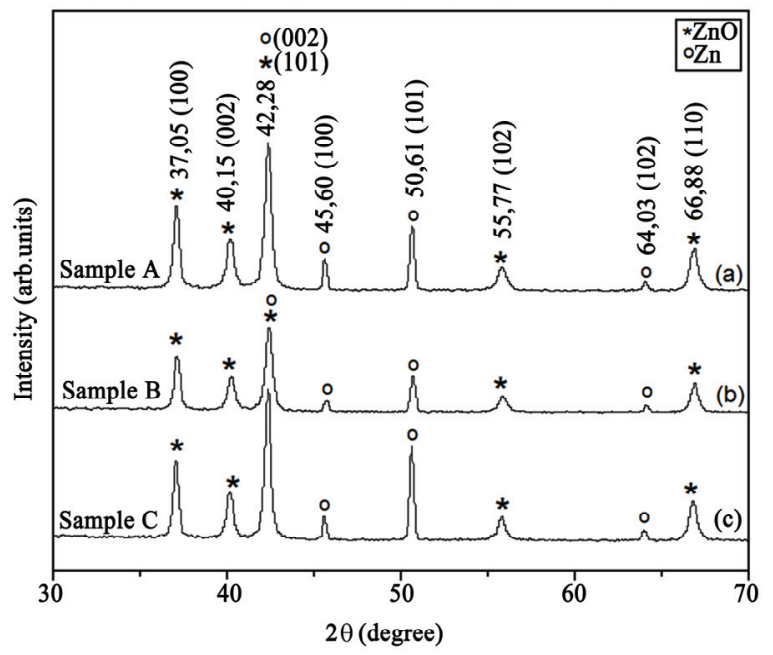

Figure 4. X-ray diffraction (XRD) patterns of samples A, B and $\mathrm{C}$ obtained from thermal oxidation of $\mathrm{Zn}$ nanowires at $300^{\circ} \mathrm{C}$ for (a) $3 \mathrm{~h}$ and (b) $6 \mathrm{~h}$, and at (c) $400^{\circ} \mathrm{C}$ for $3 \mathrm{~h}$ in air.
The XRD results indicate that all oxidised products have the same crystalline phases. The diffraction peaks at $2 \theta$ values of $37.05^{\circ}, 40.15^{\circ}, 42.28^{\circ}, 55.77^{\circ}$ and $66.88^{\circ}$ correspond to the (100), (002), (101), (102) and (110) planes, respectively, and can readily be indexed to wurtzite structured $\mathrm{ZnO}$ from ICDD-JCPDS. On the other hand, there are also diffraction peaks at $2 \theta$ values of $42.28^{\circ}, 45.60^{\circ}, 50.61^{\circ}$ and $64.03^{\circ}$ corresponding to the (002), (100), (101) and (110) planes of hexagonal zinc (ICDD-JCPDS), respectively. No peaks corresponding to other materials were detected in the patterns.

The values of the lattice parameters $a$ and $c$ calculated from the XRD spectra are shown in Table $\mathbf{1}$ and are in agreement with the JCPDS, although experimental errors were observed (the lattice parameters for $\mathrm{Zn}$ and $\mathrm{ZnO}$ from the JCDS files are $a=b=0.2665 \mathrm{~nm}$ and $c=$ $0.4947 \mathrm{~nm}$ and $a=b=0.3249 \mathrm{~nm}$ and $c=0.5206 \mathrm{~nm}$, respectively).

Quantitative phase analyses of the oxidation products were performed by fitting the individual phase contributions and weighing them with the total diffraction area from the XDR data (Figure 4); the results are reported in Table 1. These results demonstrate that all samples were oxidised after heat treatment. Sample A presented the highest rate of conversion of $\mathrm{Zn}$ nanowires into $\mathrm{ZnO}$, with $99 \%$ of the material converted into the $\mathrm{ZnO}$ phase. On the other hand, the $\mathrm{ZnO}$ content of samples $\mathrm{B}$ and $\mathrm{C}$ were reduced to about $90 \%$ and $82 \%$, respectively. The sharpness of the diffraction peaks indicates the good crystallinity of the as-grown crystallites, and the low background fingerprint indicates a small amount of amorphous phases.

The successful synthesis of $\mathrm{ZnO}$ nanowires from the oxidation of $\mathrm{Zn}$ nanowires was also confirmed by FTIR

Table 1. Relative phase weighting fractions and lattice parameters $a$ and $c$ calculated from XRD patterns of samples $\mathrm{A}, \mathrm{B}$ and $\mathrm{C}$ obtained from thermal oxidation of $\mathrm{Zn}$ nanowires at $300^{\circ} \mathrm{C}$ for $3 \mathrm{~h}, 300^{\circ} \mathrm{C}$ for $6 \mathrm{~h}$, and $400^{\circ} \mathrm{C}$ for $3 \mathrm{~h}$, respectively. The number in parentheses represents the error on the last digit.

\begin{tabular}{ccccc} 
Sample & Phases & $\begin{array}{c}\text { Phase weight } \\
\text { fractions }\end{array}$ & $\begin{array}{c}\text { Lattice parame- Lattice parameter } \\
\text { ter } a=b(\mathrm{~nm})\end{array}$ & $c(\mathrm{~nm})$ \\
\hline $\mathrm{A}$ & $\mathrm{Zn}$ & 0.9 & $0.2627(1)$ & $0.4887(1)$ \\
& $\mathrm{ZnO}$ & 99.0 & $0.3236(1)$ & $0.5186(1)$ \\
& & & & \\
$\mathrm{B}$ & $\mathrm{Zn}$ & 10.0 & $0.2598(1)$ & $0.4846(1)$ \\
& $\mathrm{ZnO}$ & 90.0 & $0.3250(1)$ & $0.5209(1)$ \\
& & & & \\
$\mathrm{C}$ & $\mathrm{Zn}$ & 18.0 & $0.2660(2)$ & $0.4943(1)$ \\
& $\mathrm{ZnO}$ & 82.0 & $0.3226(1)$ & $0.5170(1)$ \\
\hline
\end{tabular}


analyses, and the spectra are shown in Figure 5. All oxidised samples present an absorption band centred at 440 $\mathrm{cm}^{-1}$, related to the stretching mode of Zn-O [16]. In addition, all spectra showed a band of different shapes and intensities between 3700 and $3200 \mathrm{~cm}^{-1}$, which is attributed to the $\mathrm{O}-\mathrm{H}$ stretching mode.

Figure 5(a) shows absorption bands at 2370 and 2340 $\mathrm{cm}^{-1}$, representing atmospheric $\mathrm{CO}_{2}$ adsorbed onto sample A. The presence of absorption bands between 2000 and $750 \mathrm{~cm}^{-1}$ in Figure 5(c) suggests that sample C contained some impurities. The FTIR spectra results are in agreement with the $\mathrm{ZnO}$ contents obtained with the $\mathrm{X}$-ray diffraction results (Table 1).

Figures 6(a, c, e) and Figures 6(b, d, f) show SEM micrographs of samples $\mathrm{A}, \mathrm{B}$ and $\mathrm{C}$ at low magnification $($ scale bar $=1 \mu \mathrm{m})$ and high magnification (scale bar $=$ $200 \mathrm{~nm}$ ), respectively, and reveal the morphologies of the products obtained from step 2 of the process (i.e., the oxidation of $\mathrm{Zn}$ nanowires under different conditions, as shown in Figure 1). After heat treatment, the morphologies of the $\mathrm{ZnO}$ nanowires generally changed compared to those of the $\mathrm{Zn}$ nanowires (Figure 3). According to Figure 6(b), the new product obtained after oxidation for $3 \mathrm{~h}$ in air at $300^{\circ} \mathrm{C}$ (sample A) presented a filamentary morphology, and a large quantity of wire-like structures with short lengths can be observed. The diameters of the wires varied from 45 to $60 \mathrm{~nm}$. However, when the oxidation time was increased from $3 \mathrm{~h}$ (sample A) to $6 \mathrm{~h}$ (sample B) at $300^{\circ} \mathrm{C}$, wires with shorter lengths were obtained, as can be seen in Figure 6(e). The micrography

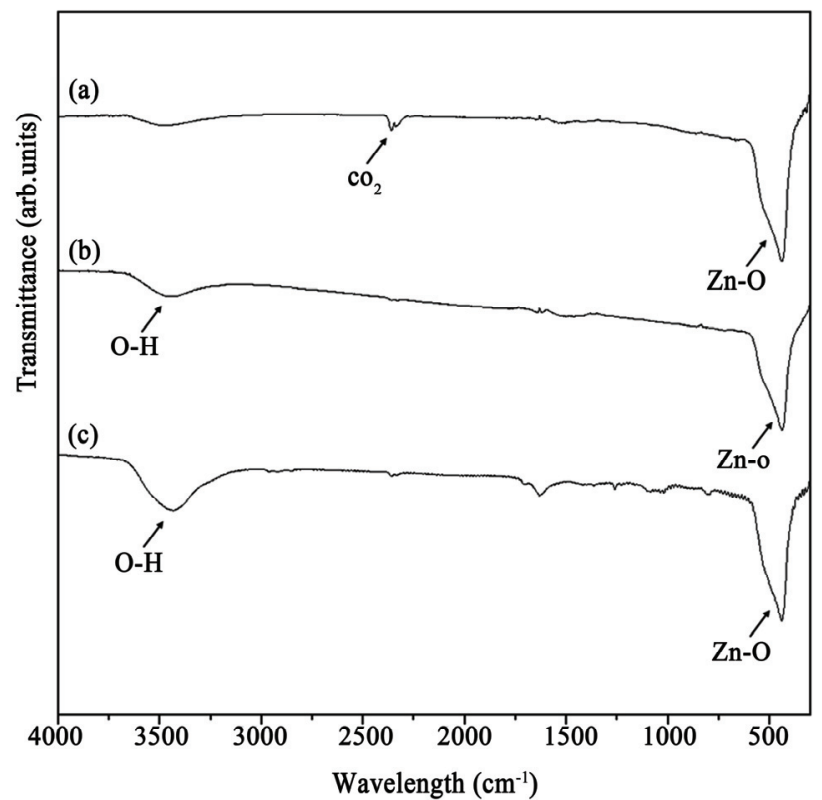

Figure 5. FTIR spectra of samples $A, B$ and $C$ obtained from thermal oxidation of $\mathrm{Zn}$ nanowires at $300^{\circ} \mathrm{C}$ for (a) $3 \mathrm{~h}$ and (b) $6 \mathrm{~h}$ and at (c) $400^{\circ} \mathrm{C}$ for $3 \mathrm{~h}$ in air.
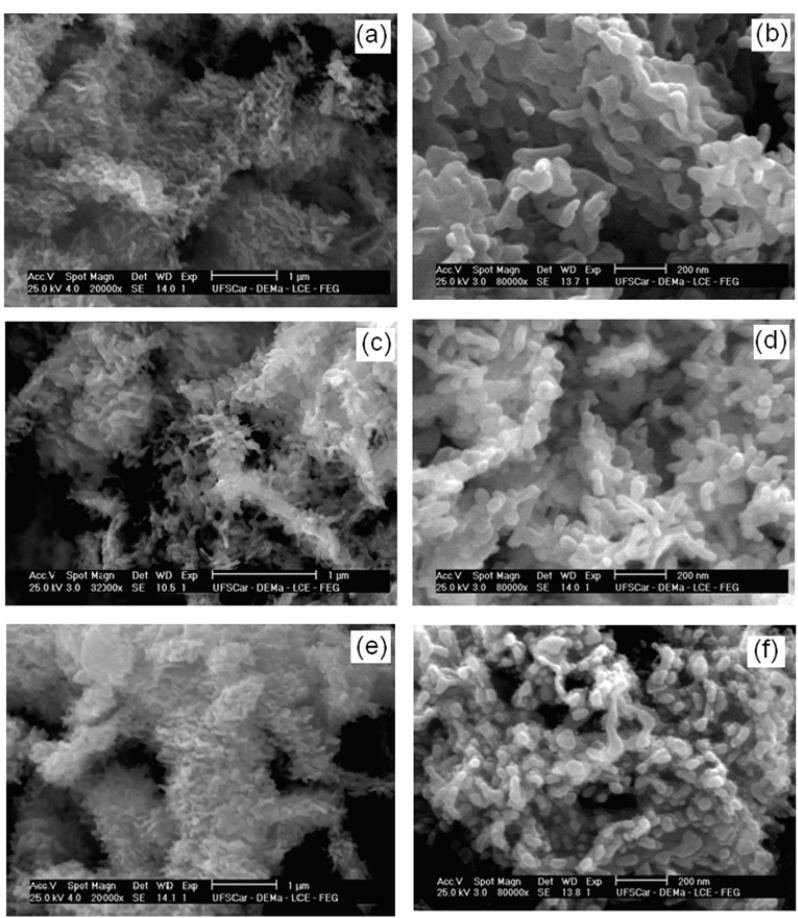

Figure 6. SEM images of samples $A, B$ and $C$ obtained from thermal oxidation of $\mathrm{Zn}$ nanowires at $300^{\circ} \mathrm{C}$ for $(\mathrm{a}, \mathrm{b}) 3 \mathrm{~h}$ and (c,d) $6 \mathrm{~h}$ and at $(\mathrm{e}, \mathrm{f}) 400^{\circ} \mathrm{C}$ for $3 \mathrm{~h}$ in air.

of sample C in Figure 6(f) reveals that the nanowires suffered partial collapse after the oxidation temperature was increased from 300 to $400^{\circ} \mathrm{C}$.

Figures 7(a-c) shows the EDS spectra of samples A, B and $\mathrm{C}$, respectively, and reveal the presence of $\mathrm{Zn}$ and $\mathrm{O}$ atoms, demonstrating once again that the $\mathrm{Zn}$ nanowires were converted to $\mathrm{ZnO}$. Peaks related to $\mathrm{C}$ and $\mathrm{Au}$ should be the contributions of the carbon grid and the film that coated the samples, respectively.

According to the literature [14], $\mathrm{ZnO} /$ biopitch pyrolysis causes the evolution of gases such as $\mathrm{H}_{2} \mathrm{O}$, oxygenated compounds, light hydrocarbons, $\mathrm{CO}_{2}$ and $\mathrm{CO}$. The special coke $\left(\mathrm{CH}_{\mathrm{x}}\right)$ generated in situ reduces $\mathrm{ZnO}$ into $\mathrm{Zn}$ through the carbothermal reduction process described by the following reaction:

$$
\mathrm{CH}_{\mathrm{x}(\mathrm{s})}+\mathrm{ZnO}_{(\mathrm{s})} \rightarrow(\mathrm{x} / 2) \mathrm{H}_{2(\mathrm{~g})}+\mathrm{CO}_{(\mathrm{g})}+\mathrm{Zn}_{(\mathrm{v})}
$$

The gases $\mathrm{H}_{2}$ and $\mathrm{CO}$ produced in reaction (1) also promote $\mathrm{ZnO}$ reduction and prevent $\mathrm{Zn}$ reoxidation as follows:

$$
\begin{gathered}
\mathrm{ZnO}_{(\mathrm{s})}+\mathrm{CO}_{(\mathrm{g})} \rightarrow \mathrm{Zn}_{(\mathrm{g})}+\mathrm{CO}_{2(\mathrm{~g})} \\
\mathrm{ZnO}_{(\mathrm{s})}+\mathrm{H}_{2(\mathrm{~g})} \rightarrow \mathrm{Zn}_{(\mathrm{g})}+\mathrm{H}_{2} \mathrm{O}_{(\mathrm{g})}
\end{gathered}
$$

The $\mathrm{Zn}$ vapour generated during the process was carried by the flow gas and deposited as $\mathrm{Zn}$ nanowires on the inner wall of the quartz tube through homogeneous nucleation at a low temperature in the absence of a template and without a catalyst. 


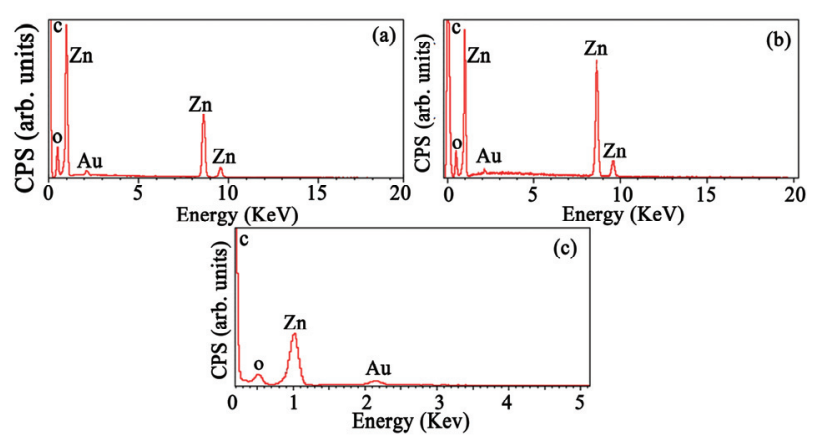

Figure 7. EDS spectra of samples $\mathrm{A}, \mathrm{B}$ and $\mathrm{C}$ obtained from thermal oxidation of $\mathrm{Zn}$ nanowires at $300^{\circ} \mathrm{C}$ for (a) $3 \mathrm{~h}$ and (b) $6 \mathrm{~h}$ and at (c) $400^{\circ} \mathrm{C}$ for $3 \mathrm{~h}$ in air.

Thus, the as-synthesised $\mathrm{Zn}$ nanowires were oxidised into nanostructured $\mathrm{ZnO}$ at relatively low temperatures $\left(300^{\circ} \mathrm{C}\right.$ or $\left.400^{\circ} \mathrm{C}\right)$ under an ambient air atmosphere:

$$
\mathrm{Zn}_{(\mathrm{s})}+1 / 2 \mathrm{O}_{2} \rightarrow \mathrm{ZnO}_{(\mathrm{s})}
$$

The mechanism proposed above is consistent with the experimental results.

\section{Conclusions}

$\mathrm{ZnO}$ nanowires were obtained with a green, two-step process: 1) the production of $\mathrm{Zn}$ nanowires by carbothermal reduction through heating a mixture of $\mathrm{ZnO}$ powder and biopitch (Eucalyptus sp. tar pitch), and 2) the oxidation in air of the as-prepared $\mathrm{Zn}$ nanowires into $\mathrm{ZnO}$. Maximal conversion of $\mathrm{Zn}$ nanowires into $\mathrm{ZnO}$ nanowires $(99 \%)$ occurred after oxidation for $3 \mathrm{~h}$ in air at $300^{\circ} \mathrm{C}$. The morphologies of the $\mathrm{Zn}$ nanowires changed with oxidation time and temperature. The XRD results showed that all of the synthesised nanowires presented hexagonal structure and good crystallinity.

This method is simple and is assisted by Eucalyptus $s p$ tar pitch co-pyrolysis, which generates carbon with special reactivity and gases $\left(\mathrm{CO}\right.$ and $\left.\mathrm{H}_{2}\right)$ that permitted $\mathrm{ZnO}$ reduction and $\mathrm{Zn}$ nanowires formation in large scale. The oxidation occurred at low temperature. The entire process was catalyst-free and performed without a vacuum or a template. This green method will probably generate interest due to its technical and economical feasibility, environmental benefits and the great importance of nanostructured $\mathrm{ZnO}$.

\section{Acknowledgements}

Adriana Veloso Maciel acknowledges a scholarship from CNPq-Conselho Nacional de Desenvolvimento da Pesquisa (Brazil) and Petrobrás.

\section{REFERENCES}

[1] T.-J. Hsueh and C.-L. Hsu, "Fabrication of Gas Sensing devices with $\mathrm{ZnO}$ Nanostructure by the Low-Temperature Oxidation of Zinc Particles," Sensors and Actuators B: Chemical, Vol. 131, No. 2, 2008, pp. 572-576.

[2] G. G. Rusu, M. Girtan and M. Rusu, "Preparation and Characterization of Thin Films Prepared by Thermal Oxidation of Evaporated Zn Thin Films," Superlattices and Microstructures, Vol. 42, No. 1-6, 2007, pp. 116-122.

[3] N. Bouhssira, S. Abed, E. Tomasella, J. Cellier, A. Mosbah, M. S. Aida and M. Jacquet, "Influence of Annealing Temperature on the Properties of $\mathrm{ZnO}$ Thin Films Deposited by Thermal Evaporation," Applied Surface Science, Vol. 252, No. 15, 2006, pp. 5594-5597.

[4] L. Z. Pei, H. S. Zhao, W. Tan, H. Y. Yu, Y. W. Chen and Q.-F. Zhang, "Single Crystalline ZnO Nanorods Grown by a Simple Hydrothermal Process," Materials Characterization, Vol. 60, No. 9, 2009, pp. 1063-1067.

[5] G. Z. Wang, Y. Wang, M. Y. Yau, C. Y. To, C. J. Deng and D. H. L. Ng, "Synthesis of ZnO Hexagonal Columnar Pins by Chemical Vapor Deposition," Materials Letters, Vol. 59, No. 29-30, 2005, pp. 3870-3875.

[6] N. Han, P. Hu, A. Zuo, D. Zhang, Y. Tian and Y. Chen, "Photoluminescence Investigation on the Gas Sensing Property of $\mathrm{ZnO}$ Nanorods Prepared by Plasmaenhanced CVD Method," Sensors and Actuators B: Chemical, Vol. 145, No. 1, 2010, pp. 114-119.

[7] M. Biswas, E. McGlynn and M. O. Henry, "Carbothermal Reduction Growth of $\mathrm{ZnO}$ Nanostructures on SapphireComparisons between Graphite and Activated Charcoal Powders," Microelectronics Journal, Vol. 40, No. 1, 2009, pp. 259-261.

[8] D. Yuvaraj and K. N. Rao, "Selective Growth of $\mathrm{ZnO}$ Nanoeedles by Thermal Oxidation of $\mathrm{Zn}$ Microstructures," Materials Science and Engineering B, Vol. 164, No. 3, 2009, pp. 195-199.

[9] H.-Q. Liang, L. Z. Pan and Z.-J. Liu, "Synthesis and Photoluminescence Properties of $\mathrm{ZnO}$ Nanowires and Nanorods by Thermal Oxidation of Zn Precursors," Materials Letters, Vol. 62, No. 12-13, 2008, pp. 17971800 .

[10] Z. H. Wang, D. Y. Geng and H. Z. D. Zhang, "Characterization and Optical Properties of $\mathrm{ZnO}$ Nanoparticles Obtained by Oxidation of $\mathrm{ZnO}$ Nanoparticles," Materials Letters, Vol. 63, No. 29, 2009, pp. 2533-2535.

[11] Z. W. Li, W. Gao and R. J. Reeves, "Zinc Oxide Films by Thermal Oxidation of Zinc Thin Films," Surface and Coating Technology, Vol. 198, No. 1-3, 2005, pp. 319323.

[12] W. Gao and Z. W. Li, "Photoluminescence Properties of ZnO Films Grown by Wet Oxidation: Effect of Processing," Journal of Alloys and Compounds, Vol. 449, No. 1-2, 2008, pp. 202-206.

[13] A. Khan and M. E. Kordesch, "Large-Scale Fabrication of Metallic Zn Nanowires by Thermal Evaporation," Physica E, Vol. 33, No. 1, 2006, pp. 88-91.

[14] J. V. D. S. Araújo, R. V. Ferreira, M. I. Yoshida and V. M. D. Pasa, "Zinc Nanowires Synthesized on a Large Scale by a Simple Carbothermal Process," Solid State 
Sciences, Vol. 11, No. 9, 2009, pp. 1673-1679.

[15] JCPDS-International Center for Diffraction Data. JCPDSICDD 2000.

[16] Y. J. Kwon, K. H. Kim, C. S. Lim and K. B. Shim,
"Characterization of $\mathrm{ZnO}$ Nanopowders Synthesized by the Polymerized Complex Method via an Organochemical Route," Journal of Ceramic Processing Research, Vol. 3, No. 3, 2002, pp. 146-149. 